\title{
Pemberdayaan Masyarakat Melalui Pengolahan Kulit Kakao
}

\author{
Nurul Inayah1, Nur Anim Jauhariyah2, Komarudin'3, Mahbub4 \\ IAI Darussalam Blokagung Banyuwangi \\ Email:1ninailzam2015@gmail.com,2animjauhariyah@gmail.com, \\ ${ }^{3}$ komarudin.a06@gmail.com, ${ }^{4} 08$ mahbubnawawi@gmail.com
}

\begin{abstract}
Sumberagung Village is one of the villages in Banyuwangi Regency which is in the southern region precisely at the foot of Mount Tumpang Pitu, Mount Lompong, Mount Bayur, and Bukit Kapur (Gunung Gamping). The village has the potential of cocoa plants. There is a problem of wasted cocoa skin waste, so we took the initiative to help the community to reduce cocoa skin waste by utilizing food preparations that could add to the economy in Sungailembu Hamlet. So that the cocoa skin waste will have a high selling value, and can be used as a typical product of the Sungailembu Hamlet. Therefore, to help with the problem of reducing cocoa skin waste, a training was held in Sungailembu Hamlet, which was attended by IIK (Employees 'Wives' Association) housed in the Punta Dewa building. By giving direction on the innovation of cocoa skin waste to be processed into cocoa skin crackers.
\end{abstract}

Keywords: Cocoa Skin, Innovation, Empowerment

\section{Pendahuluan}

Desa Sumberagung salah satu desa di Kabupaten Banyuwangi yang berada di wilayah bagian selatan tepatnya di kaki Gunung Tumpang Pitu, Gunung Lompong, Gunung Bayur, dan Bukit Kapur (Gunung Gamping). Desa Sumberagung memiliki jarak dari pusat pemerintah kabupaten sepanjang 65 km. Secara administratif Desa Sumberagung masuk di wiayah Kecamatan Pesanggaran, dengan batas-batas Sebelah utara berbatasan dengan Desa Barurejo, Sebelah selatan berbatasan dengan Samudera Indonesia, sebelah timur berbatasan dengan Desa Sumbermulyo dan Desa Pesanggaran, sebelah barat berbatasan dengan Desa Kandangan, dan Desa Sarongan. ${ }^{1}$

${ }^{1}$ Profil Desa Sumberagung. 2018. 
Desa dengan luas wilayah 13.262ha, Desa Sumberagung merupakan desa yang cukup luas wilayahnya dari Kabupaten Banyuwangi. Desa Sumberagung termasuk daerah yang memiliki banyak kekayaan alami atau sumber daya alam tertinggi. Hampir seluruh kekayaan alam dimiliki oleh desa Sumberagung, sumber daya yang dimiliki desa Sumberagung ini antara lain mulai dari kelautan (wilayah dusun pancer, pulau merah), Kehutanan (membentang disekitar wilayah dusun Sungai Lembu), pertanian, pariwisata, dan pertambangan (di Gunung Tumpang Pitu) yang terdapat biji emas dan yang saat ini telah dilakukan eksplorasi oleh PT Bumisuksesindo (BSI). ${ }^{2}$ Dalam pembangunan Desa Sumberagung baik pembangunan fisik dilaksanakan guna meningkatkan perekonomian masyarakat Desa Sumberagung yang kedepannya bisa meningkatkan taraf hidup masyarakat.

Desa Sumberagung dengan populasi penduduk sebanyak 9,721 jiwa dengan mata pencaharian utama dibidang pertanian selalu berupaya agar tidak terlalu tertinggal, utamanya dalam hal informasi dan pembangunan. Dari berbagai upaya pembangunan yang sudah dilaksanakan di Desa Sumberagung tersebut baik fisik maupun non-fisik hingga sekarang masih jauh dari harapan dalam memenuhi kebutuhan masyarakat pada umumnya. Hal tersebut dibuktikan dengan masih tingginya angka keluarga miskin atau kaum Duafa yang mencapai 984 kelapa rumah tangga yang belum bisa tercukupi daam bentuk sarana dan prasarana penunjang kegiatan ekonomi. Beberapa kegiatan pembangunan belum mampu memenuhi kebutuhan masyarakat Desa Sumberagung secara maksimal, akan tetapi dari beberapa kegiatan yang telah diadakan oleh perangkat desa juga membantu sedikit sumbangsih yang lumayan besar bagi pembangunan dan kemajuan Desa Sumberagung. 4

\footnotetext{
2 ibid

3 BPS Kabupaten Banyuwangi, 2018.

${ }^{4}$ Profil Desa Sumberagung. 2018.
} 
Permasalahan yang kini terjadi di dusun sungailembu yaitu tentang perekonomian, karena mayoritas masyarakat disana bekerja sebagai buruh dan karyawan di perkebunan. Sehingga pendapatan masyarakat disana sangat minim sekali, oleh karena itu masyarakat disana bukan hanya bekerja diperkebunan saja, akan tetapi sebagian warga ada yang bekerja di pabrik pembuatan gula merah guna untuk menambah hasil perekonomian.

Sehingga penghasilan terbesar Dusun sungailembu adalah hasil perkebunan, seperti kulit kakao yang terdiri dari kulit buah, keeping biji dan plasenta. Kulit kakao merupakan bagian terbesar dari buah kakao. Buah kakao terdiri dari 75\% kulit buah, 3\% plasenta, 22\% biji, dengan semakin meningkatnya produksi biji kakao, mengakibatkan semakin meningkatnya kulit buah kakao yang terbuang. Adapun manfaat kulit buah kakao mengobati kanker, menurunkan tekanan darah, menyehatkan jantung, menurunkan kadar kolestrol, anti obesitas, mengobat stress, mengobati diare. permasalahanya adalah ketika memasuki musim panen, buah kulit kakao mengalami peningkatan jika terjadi pada musim hujan, sehingga kandungan yang ada dikulit kakao semakin banyak dan kulitnya terlihat bersih seperti kulit kakao yang normal. Sedangkan jika mengalami musim kemarau panjang kulit kakao akan berpegaruh mengalami dampak yang jelek pada buah yang akan dipanen, meliputi banyak bintik-bintik, kurangnya kandungan air yang ada pada buah kakao. ${ }^{5}$

Maka dari itu, melalui RPJMDesa masyarakat Desa Sumberagung sangat mengharapkan bahwa program-pprogram pembangunan yang telah tersusun secara partisipatf ini menjadi agenda pembangunan selama lima tahun ke depan ini betul-betul mampu mendongkrak kebutuhan masyarakat. Tentunya pula perhatian serta dukungan biaya dari pemerintah maupun pihak ketiga yang turut andil dalam pembangunan Desa Sumberagung.

Dengan adanya permasalahan limbah kulit kakao yang terbuang, maka

${ }^{5}$ Profil Desa Sumberagung. 2018. 
kami berinisiatif untuk membantu masyarakat untuk mengurangi limbah kulit kakao dengan memfaatkan dalam olahan makanan yang bisa menambah perekonomian yang ada di dusun sungailembu. Sehingga limbah kulit kakao akan memiliki nilai jual yang tinggi, dan bisa dijadikan produk khas dari sungailembu. Limbah kulit kakao merupakan limbah yang sulit diatasi dimana sering berdampak membuat kerugian dari pada keuntungan, salah satu manfaat limbah kulit kakao bisa diolah beraneka makanan, diantaranya pembuatan kerupuk kakao. Oleh karena itu, untuk membantu masalah pengurangan limbah kulit kakao maka diadakan pelatihan di Dusun Sungailembu yang dihadiri oleh ibu-ibu IIK (Ikatan Istri Karyawan) yang bertempat di gedung Punta Dewa. Dengan memberi arahan tentang inovasi limbah kulit kakao untuk diolah menjadi kerupuk kulit kakao.

\section{Metode}

Dengan adanya pelatihan ini masyarakat dusun Sungailembu kedepannya dapat melanjutkan inovasi limbah kakao dalam berbagai macam olahan, sehingga dapat menghasilkan skill serta menambah pengalaman yang dapat dijadikan bisnis rumahan untuk meningkatkan perekonomian masyarakat sungailembu. Berdasarkan masalah yang sudah diteliti, kami akan membantu masyarakat untuk memecahkan masalah dengan membuat pohon masalah.

Salah satu inti dari permasalahan diatas kurangnya pemanfaatan limbah yang terbuang yang tidak di inovasi dalam berbagai olahan, jika dalam setiap bulan petani perkebunan memanen kakao cukup banyak, maka semakin banyak limbah kulit kakao yang terbuang, oleh karena itu perlu adanya penyuluhan untuk masyarakat terkait dengan limbah kakao yang tidak mempunyai harga jual menjadi bernilai keuntungan yang besar.

Oleh karena itu, dengan mengapresiasikan peningkatan perekonomian masyarakat yang ada di sungailembu. Salah satunya dengan memanfaatkan 
limbah kulit kakao yang tidak bernilai menjadi bernilai tinggi. Maka kami berinisiatif untuk memberi arahan kepada ibu-ibu IIK (ikatan istri karyawan) dalam pembuatan olahan krupuk kakao menjadi aneka makanan. Harapan kedepanya masyarakat di sungailembu dapat menginovasikan lebih baik lagi, guna untuk meningkatkan daya saing yang semakin meluas dan memberikan dampak yang positif bagi masyarakat sungailembu.

Untuk cara pengolahan limbah kulit kakao cukup mudah, tapi bagi masyarakat yang belum mengetahui cara pengolahan perlu adanya dampingan khusus. Pertama perlu adanya pengetahuan atau materi untuk menunjang agar ibu-ibu IIK (ikatan istri karyawan) lebih paham bagaimana cara pengolahan yang baik, bukan sekedar pengetahuan tapi perlu adanya praktik yang akan dijadikan acuan dalam pengolahan limbah kakao. sasaran untuk menjalankan program ini yaitu:

1. Ibu-ibu IIK (Ikatan Istri Karyawan)

IIK (Ikatan Istri Karyawan) merupakan sebuah organisasi yang beranggotakan istri para karyawan dusun sungailembu, kegiatan Ibu-ibu Migrant Care selain arisan rutin setiap hari jum'at yaitu berkumpul dan membuat olahan dari hasil perkebunan yang ada di dusun sungailembu seperti olahan sirup jahe. Untuk memberikan inovasi kepada ibu-ibu IIK dan memanfaatkan limbah kulit kakao yang banyak terdapat di perkebunan Dusun Sungailembu maka berinisiatif untuk memberikan pengetahuan dan pelatihan tentang olahan krupuk kulit kakao dan menjadikan ibu-ibu IIK sebagai sasaran olahan pembuatan krupuk kakao.

Dusun sungailembu terdapat perkebunan PTPN XII yang didalamnya banyak sekali limbah kulit kakao yang terbuang. Maka dengan melaksanakan program dengan sasaran ibu- ibu IIK dapat memberikan inovasi olahan produk di dusun tersebut.

2. Ibu-ibu Migrant Care 
Sasaran program selanjutnya adalah ibu-ibu Migrant Care, di Dusun Silirbaru terdapat perkumpulan ibu-ibu mantan TKI yang terkumpul dalam ikatan ibu-ibu Migrant Care.

\section{Strategi Pelaksanaan Program}

Agar program terlaksana sesuai dengan baik dan mendapat antusias dari warga, beberapa strategi dalam pelaksanaan program dengan meningkatkan inovasi limbah kakao untuk pembuatan krupuk dan pemanfaatan buah naga yang memiliki harga jual cukup murah dan mengadakan penyuluhan kepada ibu-ibu IIK dan ibu-ibu Migrant Care yang berada didusun sungailembu dan Dusun Silirbaru, yang mana penyuluhan diadakan digedung dan diarea perumahan sekitar warga.

\section{Hasil dan Diskusi}

Tanggal 22 September 2019 diadakannya pelatihan sebagai upaya lanjutan dari sosialisasi yang telah disampaikan pada tanggal 16 September 2019. Tentang pembuatan dan pemasaran kerupuk kulit kakao yang kelompok 18 selenggarakan bersama IIK (Ikatan Istri Karyawan) di gedung Punta Dewa dusun Sungailembu.

Musyawarah dalam hal ini diakhiri dengan praktik pembuatan kerupuk kulit kakao dari peserta KKN-PAR Ibu-ibu Migrantcaredesa Sumberagung bersama ibu-ibu IIK dusun Sungailembu secara simbolis sebagai tanda kerja sama antara masyarakat dengan peserta KKN-PAR kelompok 18. Setelah pelatihan pembuatan dan pemasakan kerupuk kulit kakao selesai maka tahap selanjutnya yang dilakukan adalah melakukan penjemuran bersama para ibu-ibu, dengan di dukung oleh elemen-elemen yang terkait di salah satu halaman milik warga demi kesuksesan penjemuran. Adapun resep dan langkah-langkah pembuatan kerupuk kulit kakao sebagai berikut:

\section{Tabel 4.1 Resep Pembuatan Kerupuk Kulit Kakao}




\begin{tabular}{|c|l|l|}
\hline $\begin{array}{c}\mathrm{N} \\
\mathrm{o}\end{array}$ & Nama bahan & Takaran \\
\hline 1 & Tepung tapioca (kanji) & $1 / 2 \mathrm{~kg}$ \\
\hline 2 & Tepung terigu & $1 / 2 \mathrm{~kg}$ \\
\hline 3 & Kulit kakao & $1 / 2 \mathrm{~kg}$ \\
\hline 4 & Ketumbar & $2 \mathrm{sdm}$ \\
\hline 5 & Bawang putih & 1 bongkol \\
\hline 6 & Garam & Secukupnya \\
\hline 7 & Penyedap rasa & Secukupnya \\
\hline
\end{tabular}

Sumber: Dokumentasi, 2019

Peralatan yang diperlukan: Pisau, dandang, blender, alat penggepit, ember kecil, plastik dan tali raffia. Langkah-langkah membuat kerupuk kulit kakao:

1) Haluskan dan campurkan bumbunya: bawang putih, garam, penyedap rasa, dan ketumbar. (sisihkan)

2) Memilih kulit kakao yang bagus dan segar. Kemudian kulit kakao mentah tersebut dikupas

3) Hasil kupasan kulit kakao dikukus \pm 20 menit (hingga kulit kakao lunak)

4) Iris tipis-tipis kulit kakao yang telah dikukus kemudian blender dengan air secukupnya. (hingga halus dan sisihkan)

5) Campurkan terigu, tapioca dan hasil blender kulit kakao aduklah hingga merata.

6) Masukkan bumbunya pada langkah 1 .

7) Kemudian aduklah hingga merata...

8) Masukkan adonan ke dalam plastik dan ikat dengan tali raffia serta diberi lubang- lubang kecil.

9) Rebuslah selama \pm 20 menit (sampai terapung) 
10) Angkat adonan yang sudah matang,kemudian di penyet dengan alat penggepit

11) Jemurlah hasil langkah 10 dibawah terik sinar matahari langsung \pm 1 hari. (kerupuk kulit kakao siap digoreng)

12) Sebelum kerupuk digoreng, haruslah dijemur sebentar terlebih dahulu supaya kerupuk dapat mengembang dengan sempurna.

13) Kerupuk siap untuk dikemas sesuai kebutuhan.

Berikut ini merupakan dokumentasi dari proses dan langkah-langkah pembuatan kerupuk tahu gambir :
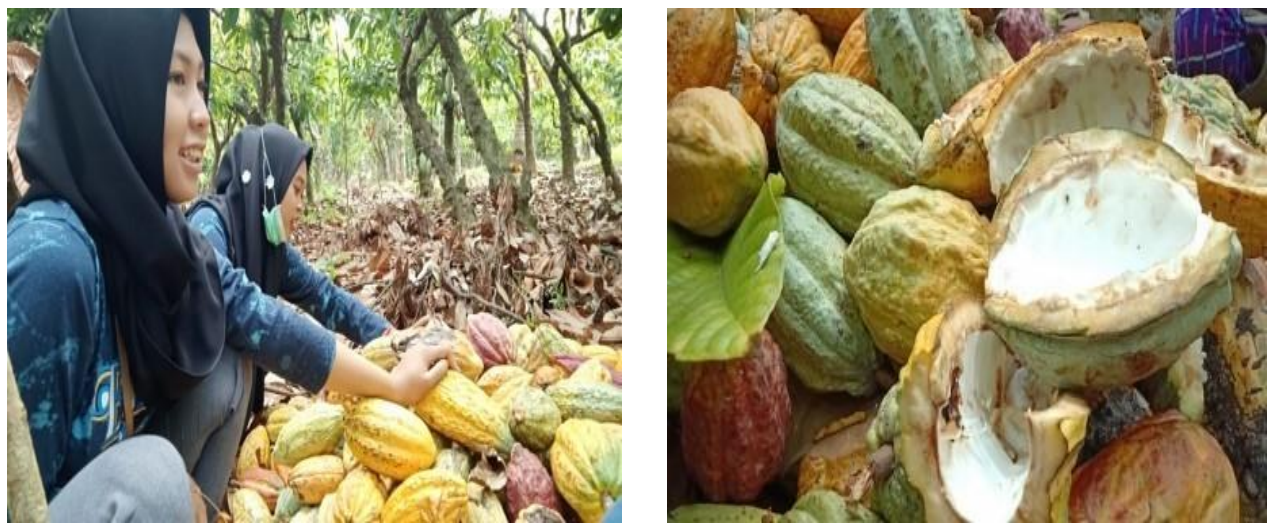

Gambar 1. Survey Kulit Kakao di Perkebunan (Sumber: Dokumentasi, 2019)

Dalam gambar tersebut, kami terjun ke perkebunan guna melihat atau mensurvey langsung bagaimana kegiatan ibu-ibu karyawan lepas guna mengetahui perekonomian serta mengorek seberapa besar limbah yang terbuang dalam setiap harinya. Dalam pembuatan Kerupuk kulit kakao pastinya tetap membutuhkan bumbu-bumbu guna menambah cita rasa kerupuk kulit kakao tersebut, yakni ada kulit kakao sebagai bahan utama pembuatan kerupuk kulit kakao, ada tepung terigu untuk pencampurannya, tepung tapioka, ditambahkan bawang untuk salah satu bumbu tumbuknya 
dan rasanya, ketumbar, dan ada garam. Dalam hal ini, bisa ditambah dengan penyedap rasa seperti Royco atau Masako.

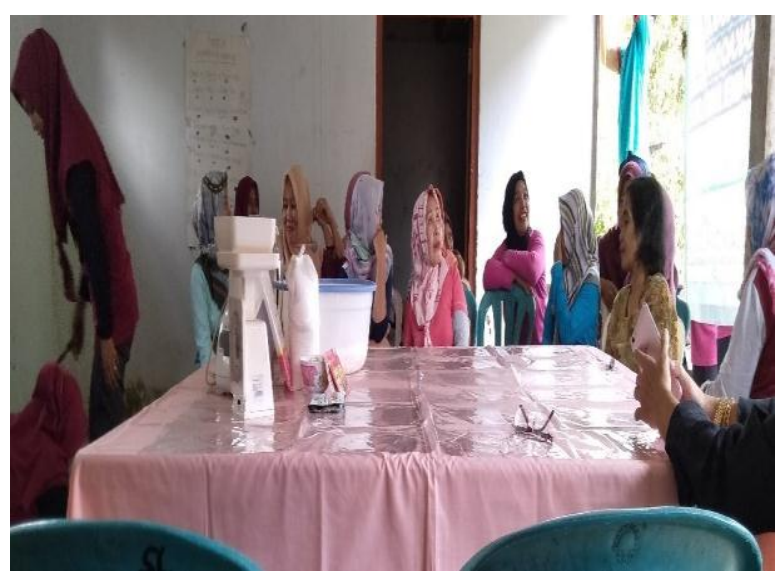

\section{Gambar 2. Proses Pembuatan Kerupuk Kulit Kakao Bersama ibu-ibu IIK} (Ikatan Istri Karyawan) Dusun Sungailembu (Sumber: Dokumentasi, 2019)

Proses akan membuat kerupuk kulit kakao bersama ibu-ibu IIK (Ikatan Istri Karyawan) dusun Sungailembu yang bertempat di Afdeling Kantor Tanggal 22 September 2019, jam 09.00. karna keantusiasan ibu-ibu IIK, seluruh bahan dan peralatan yang dibutuhkan sudah tersiapkan terlebih dahulu. Sesuai dengan urutan pembuatan kerupuk Kulit Kakao setelah dikukus kulit tersebut, maka di arsir dan ditimbang agar dari seluruh bahan sesuai dengan takaran dan seimbang. Setelah ditimbang arsiran kulit kakao tersebut di haluskan menggunakan Blander agar tidak menyita waktu lagi pula kulit kakao tersebut terlalu lembek jika menggunakan parut manual. Setelah dihaluskan melalui blander, halusan kulit kakao dihidangkan di wadah ember guna pencampuran atau pengadukan dengan bahan-bahan selanjutnya, seperti tepung terigu dan tepung tapioka, agar lebih Ibu-ibu Migrant Care dan mudah dalam pembentukannya. Selanjutnya, setelah bumbu dan bahan-bahan yang lain sudah tercampur rata, adonan basah kerupuk kulit kakao di masukkan ke panci untuk di kukus kembali selama 
kurang lebih 20 menit agar leih mengeras. Setelah itu di tiriskan dan mulai pencetakan menggunakan alat seadanya, atau biasanya memakai geprekan kerupuk puli. Setelah pencetakan selesai menjadi pipih dilanjutkan dengan proses Penjemuran \pm 1hari dibawah sinar terik matahari langsung, agar kering dan ketika di goreng lebih mengembang karena efek tepung tapioka.

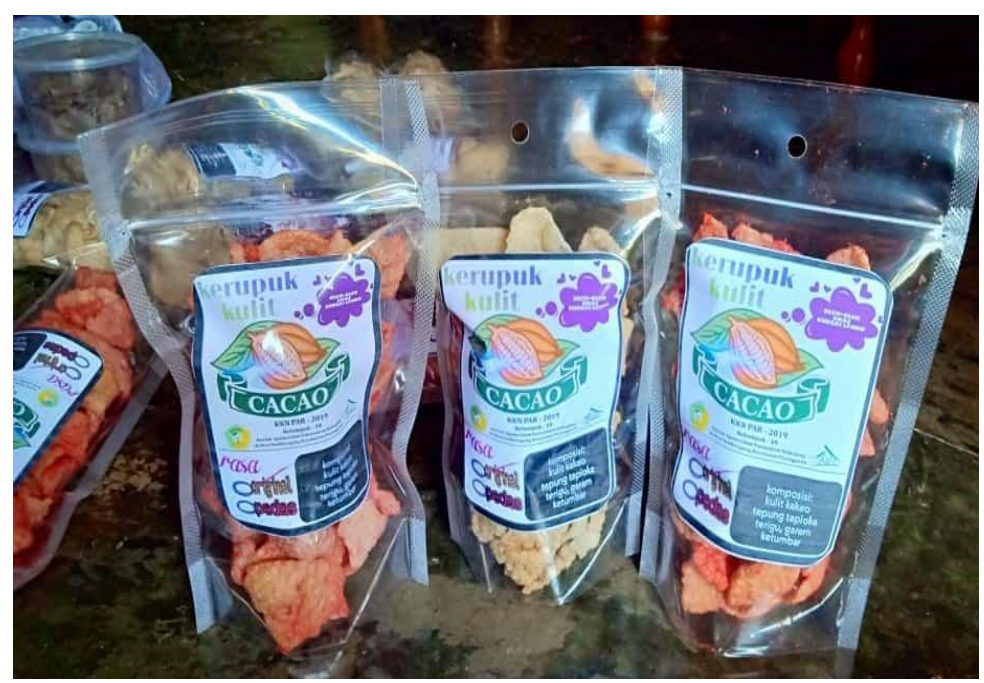

Gambar 3. Produk Kerupuk Kulit Kakao Dusun Sungailembu (Sumber: Dokumentasi, 2019)

Pengemasan serta siap pemasaran kerupuk kulit kakao di Dusun Sungailembu Desa Sumberagung. Dalam hal pemasaran untuk ibu-ibu IIK sudah mempunyai cabang diberbagai tempat.

\section{Simpulan}

Hasil pengabdian Pemberdayaan Masyarakat Melalui Pengolahan Kulit Kakao membantu dalam mengatasi limbah kakao menjadi produk makanan yang dapat membantu ekonomi masyarakat khususnya ibu-ibu IIK di Dusun Sungailembu, Desa Sumberagung, Kecamatan Pesanggaran, Kabupaten Banyuwangi.

\section{Daftar Referensi}


BPS Kabupaten Banyuwangi. Banyuwangi dalam Angka Tahun 2018

Tim Penyusun, Profil Desa Sumberagung Kecamatan Pesanggaran Kabupaten Banyuwangi Tahun 2018

Tim Penyusun, 2018, Pedoman Kuliah Kerja Nyata Partisipatory Action Research (KKN-PAR), LPPM-IAIDA, Banyuwangi : IAIDA Press 